DOI: $\underline{10.20472 / E S .2020 .9 .1 .006}$

\title{
SOFT SKILLS AND EARNINGS: EVIDENCE FROM A NATIONWIDE SURVEY IN POLAND
}

\author{
ALICJA GRZEŚKOWIAK
}

\begin{abstract}
:
The purpose of this paper is to examine differences in earnings in Poland with respect to the level of soft skills. The study is based on data from a nationwide survey on human capital carried out in 2014. Eight types of soft skills are taken into consideration: entrepreneurship and showing initiative, resistance to stress, cooperation in a group, communicativeness, ability to resolve conflicts, coordination of the work of other employees, creativity and continuous learning of new things. Distributions of earnings corresponding to groups of individuals declaring low, medium and high soft skills are compared by statistical methods, namely by kernel estimation, one-way ANOVA on ranks and relative distributions. The analysis leads to the conclusion that earnings distributions vary substantially with regard to the level of soft skills. The biggest differences concern such skills as entrepreneurship and showing initiative, coordination of the work of other employees and creativity. This paper contributes to the knowledge about the associations between soft skills level and earnings.
\end{abstract}

\section{Keywords:}

soft skills, earnings, non-parametric methods, kernel estimation, relative distributions

JEL Classification: J24, J31

\section{Authors:}

ALICJA GRZEŚKOWIAK, Wrocław University of Economics and Business, Poland, Email: alicja.grzeskowiak@ue.wroc.pl

\section{Citation:}

ALICJA GRZEŚKOWIAK (2020). Soft skills and earnings: evidence from a nationwide survey in Poland. International Journal of Economic Sciences, Vol. IX(1), pp. 102-120., 10.20472/ES.2020.9.1.006 


\section{Introduction}

Knowledge and skills - essential elements of human capital - have a key role in stimulating economic growth and affect well-being and social cohesion (Healy and Côté, 2001). Resources of knowledge and competences influence the success of individuals and societies, especially in the information era. In a rapidly changing world, human capital continues to gain importance. Having and developing specific skills becomes necessary in the labor market and gives individuals a competitive advantage. A common approach is to divide skills into hard and soft ones. Hard competences and their influence on the labour market outcomes are better recognized and described. Fewer quantitative studies are dedicated to soft skills and their impact on workers' situation, especially in terms of financial gains. In times of the growing role of soft skills, it gives the rationale for undertaking research in this field.

The main objective of this study was to examine the differences in earnings in Poland in relation to the declared level of soft skills (categorized as low, medium and high). Several specific objectives supporting the principal one were also formulated:

- to assess the properties of the earnings distributions by different levels of soft skills,

- to check if there are statistically significant differences in earnings for groups characterized by different levels of soft skills,

- to evaluate if the shapes of earnings distributions are similar or not for groups characterized by different levels of soft skills,

- to identify soft skills for which the differences in earnings are the highest.

The study was based on individual data from a survey conducted in Poland. Various statistical methods supported by visualization techniques were used, namely kernel estimation, nonparametric analysis of variance and relative distributions. The data analysis consisted of two stages. In the first, exploratory phase, research hypotheses were formulated. In the second stage, hypotheses were verified with statistical tools - tests and distribution comparisons.

\section{Literature review}

Historically hard skills were the only competencies indispensable for career employment, but nowadays, soft skills are found as critical for productive performance in a modern workplace (Robles, 2012). The term soft skills is ambiguous and differs from context to context (Schulz, 2008). According to Balcar (2014), the lack of the precise definition may be the result of using the term in both scientific research and business, where it is more important to mention the desired skills than to create generalizations. Moreover, the terminology is not consistent in the literature. Such expressions as life skills, transversal skills, generic competencies, transferable skills, skills for social progress are examples of terms used by institutions and organizations (Cinique as cited in Cimatti, 2016). People skills or intangibles are also common words for the description (Matteson et al., 2016). Soft skills can be defined as "interpersonal qualities, also known as people skills, and personal attributes that one possesses" (Robles, 2012, p.453). According to Cimatti soft skills are "personal transversal competences such as social aptitudes, language and communication capability, friendliness and ability of working in team and other personality traits that characterize relationships between people" (Cimatti, 2016, p. 97). Rainsbury and her 
coauthors (2002, p.9) describe them as "interpersonal, human, people, or behavioral skills" influencing personal behavior and relationships between people. Regardless of the definition, soft skills are usually perceived as complementary to hard skills which are associated with specific technical expertise and knowledge acquired during educational processes.

Labor market requirements reflect the demand for versatile competencies. Possessing both hard and soft skills becomes indispensable for obtaining and retaining employment. A European study (Andrews and Higson, 2008) reveals that it is necessary to equip business graduates with skills and abilities of different nature. Strong evidence of the associations between the level of skills and earnings can be found in the literature. However, numerous researches concern the relationships between wages and hard (cognitive) skills. This is due to the fact that hard skills are much easier to measure. Moreover, there are international and worldwide educational studies that provide high-quality data for the assessment and comparative analyses. Hanushek and Woessmann (2008) argue that cognitive skills are powerfully related to individual earnings. Another important conclusion is that skills have a big impact on economic growth. A comparative study based on data from the International Literacy Survey indicates that cognitive skills contribute to a considerable extent to the relationship between education and earnings (Barone and Van de Werfhorst, 2011). Hanushek and his coauthors (2015) analyze data from the Programme for the International Assessment of Adult Competencies (PIAAC) in 22 countries and put forward a conclusion that higher cognitive skills (numeracy, literacy, problem-solving) are associated with higher wages. However, some studies show that the role of hard competences is declining in importance. Castex and Kogan-Dechter (2014) examine data from the National Longitudinal Survey of Youth and find that the return to cognitive skills was smaller in the 2000s than in the 1980s. The differences are substantial as the decline by $30 \%-50 \%$ was observed for men and women. Using the same data Deming (2017) demonstrates that there was significant growth in the labor market return to social skills and a negative change in return for cognitive skills. Edin and his coauthors (2018) analyze unique administrative data for Sweden (1992-2013) and report that non-cognitive skills are increasingly valued by the labor market, particularly in the private sector and in the upper-end of the wage distribution. Robles (2012) refers to studies indicating that soft skills are far more important for long-term job success with the contribution estimated even to $75 \%$ or $85 \%$. The importance of non-cognitive skills for the labor market outcomes is also proved in other works, e.g. Heckman et al. (2006), Brunello and Schlotter (2011), Cobb-Clark and Tan (2011), Lindqvist and Vestman (2011), Weinberger (2014).

The growing importance and a bigger reward for soft skills incline to in-depth research on this subject in Poland. However, the evaluation of the impact on earnings encounters numerous limitations. Firstly, as already mentioned, there is no consensus on the definition and the scope of this term. Secondly, soft skills are difficult to measure and therefore relatively rarely included in quantitative research. As opposed to hard competencies, they are not represented in international surveys like PIACC. Thirdly, it is extremely difficult to obtain reliable data allowing for testing the relationship with earnings. The lack of appropriate and comprehensive methods for empirical measurement is in contrast with the acknowledgment of skills in modern economics (Borghans et al. 2001). Various approaches that overcome these limitations, at least to some extent, are proposed in the literature. Kyllonen (2013) claims that the most popular method both in scientific research and in practice is a simple self-rating scale. Other alternatives mentioned by this author 
are ratings by others, situational judgment tests, behavioral interviews and standardized tests of soft skills (still under development). Balcar (2014), in his literature overview, distinguishes two methodological approaches for measurement. The first, called direct, is to ask questions about behavior, preferences or attitudes. The second, named indirect, is based on the approximation by job tasks. The proposed solutions contribute significantly to the soft skills assessment, but many of them are limited by the availability of specific data usually accessible in surveys focused on skills or education.

Determinants of earnings are an important area of research in the Polish economic literature, but relationships with skills are rather rarely explored. In terms of human capital influence, more attention was paid to return to education. The associations between the level of skills and earnings in Poland are discussed in (Czarnik and Turek, 2015; Czarnik et al., 2011). The authors apply regression models to predict earnings on a set of variables, including self-assessment of skills. Burski and his coauthors (2013) use data from the PIAAC study to determine the competence bonuses defined as the rise of income accompanying higher competencies. The analysis is based on the comparison of income quartile groups with skills level. Relations between hard competencies and earnings are examined by a multidimensional approach by Grześkowiak (2017). A composite skills index derived from categorical principal component analysis is referred to earnings. Grześkowiak (2018) also uses nonparametric statistical methods to evaluate the differences in earnings resulting from the low and high level of hard skills. The results presented in the above-mentioned papers show the positive dependence between skills and labor market outcomes. However, the relationship between soft competences and earnings has not been thoroughly discussed yet and requires further consideration.

\section{Data and methods}

The analyses were carried out using data from a nationwide survey on the human capital in Poland named Bilans Kapitału Ludzkiego. Results from the 5th wave which took place in 2014 were taken into consideration. This wave of the survey included 17674 respondents in productive age (i.e. 18-64 for men and 18-59 for women). Unfortunately, not all of them answered all questions about earnings and skills. Therefore, the calculations were based on a reduced but complete dataset $(\mathrm{N}=6899)$.

Two types of variables were taken into account, i.e. self-assessments of soft skills and the level of net monthly earnings. Respondents evaluated their skills on the five-point ordinal scale, where 1 indicated "low" and 5 indicated "very high" level. Eight following soft competencies were considered:

- entrepreneurship and showing initiative,

- resistance to stress,

- cooperation in a group,

- communicativeness and clear expression of thoughts,

- ability to resolve conflicts among persons,

- coordination of the work of other employees,

- creativity (being innovative, coming up with new solutions),

- continuous learning of new things. 
In the further part of the paper, in order to ensure transparency in the figures and the tables, the abbreviated terms of the above-enumerated skills are used, respectively: initiative, stress, teamwork, communicativeness, conflicts, coordination, creativity, learning new things.

The responses were recoded in order to create three groups for further comparisons: low level of a particular skill (answers 1 and 2), medium level (answer 3) and high level (answers 4 and 5). On the other hand, the variable describing the earnings is measured on the ratio scale as the respondents gave the amount of their average monthly net earnings (considering the last 12 months).

The evaluation of differences in earnings in relation to the declared level of competences was carried out separately for each skill using various statistical methods. As the preliminary part of the analysis, an exploratory approach was used to determine the basic characteristics of the distributions of earnings in relation to the level of skills. Boxplots visualizations were used as a valuable tool for the assessment of dispersion, skewness and occurrence of outliers. Probability density functions were estimated since they are considered as a natural way for the informal investigation of sets of data leading to conclusions or giving hints for further analysis (Silverman, 1986). Kernel estimation was applied as a non-parametric approach not demanding the knowledge of the underlying distribution. The estimator based on $n$ observations $X_{1}, X_{2}, \ldots, X_{n}$ for a kernel $\mathrm{K}$ and a bandwidth $\mathrm{h}$ is expressed by the formula (Parzen, 1962; Rosenblatt, 1956):

$$
\hat{f}_{n}(x)=\frac{1}{n h} \sum_{i=1}^{n} K\left(\frac{x-X_{i}}{h}\right)
$$

$\mathrm{h}$ is a smoothing parameter, and $\mathrm{K}$ is usually a symmetric and unimodal function falling off to zero rapidly away from the center (Moeslund et al., 2011). Examples of typical kernels are rectangular, triangular, biweight, Gaussian, Epanechnikov, cosine (Rizzo, 2019). In this analysis, the Epanechnikov kernel was used. Kernel density estimates can be viewed as a generalization of histograms and a solution to avoid their disadvantages (Sarkar, 2008). Moreover, such estimation gives the possibility to compare several distributions on one plot, which is not possible by simple histograms commonly used in the exploratory analysis.

Boxplots and kernel density estimates served for preliminary insight into data. Next, a confirmatory approach was used. Firstly, the normality assumption was tested because its violation may lead to unreliable results, e.g. in group comparisons by t-tests or ANOVA. ShapiroWilk test (Shapiro and Wilk, 1965) was used as it is considered the most powerful normality test in the group of commonly applied tests, i.e. Shapiro-Wilk, Kolmogorov-Smirnov, Lilliefors and Anderson-Darling (Razali and Wah, 2011). The nature of data was the reason for using the nonparametric equivalent of ANOVA - Kruskal-Wallis test by ranks (Kruskal and Wallis, 1952), also called one-way ANOVA on ranks. This test involves several independent samples and allows us to tell if they have the same distributions (null hypothesis), or at least one sample differs (alternative hypothesis). Hence, if the null hypothesis was rejected, additional post hoc pairwise comparisons were performed to detect and describe the differences. For this purpose, Dunn's procedure was used (Dunn, 1964) with Bonferroni corrections of p-values.

The relative distributions theory was used to describe differences in distributions of earnings, in particular, to identify discrepancies in their shapes. The relative distribution methods are 
presented in details in (Morris et al., 1994; Handcock and Morris, 1999; Handcock and Morris, 1998). The idea is to compare two groups: the reference group and the comparison group. Random variables corresponding to these groups are denoted by $Y_{0}$ and $Y$, probability density functions $\mathrm{f}_{0}(\mathrm{y})$ and $\mathrm{f}(\mathrm{y})$, and cumulative distribution functions $F_{0}(\mathrm{y})$ and $\mathrm{F}(\mathrm{y})$, respectively. The key elements of this approach can be summarized as follows (Handcock and Morris 1999, p. 21-24):

- the relative distribution of $Y$ to $Y_{0}$ is obtained by grade transformation according to the formula:

$$
R=F_{0}(Y)
$$

- a realization of $R$ is denoted $r$ and called relative data,

- the relative probability density function is given by:

$$
g(r)=\frac{f\left(y_{r}\right)}{f_{0}\left(y_{r}\right)} y_{r}=Q_{0}(r) \geq 0
$$

where $Q_{0}(r)$ is the quantile function of $F_{0}$.

- the relative probability density function has a clear and useful interpretation as a density ratio between the fractions of individuals in the comparison and reference groups at a given level of the attribute.

Another advantage of the method is the possibility of a graphical presentation of results allowing for a visual assessment of the differences. This approach is used in various fields of study, e. g. in comparing income inequality over time or with respect to social features (Alderson et al., 2005; Alderson and Doran, 2010; Mysíková 2011), in investigating body mass index (Contoyannis and Wildman, 2007), in assessing changes over time in the distribution of socioeconomic status (Kabudula et al., 2007), in comparing earnings in relation to the level of hard competencies (Grześkowiak, 2018). In this paper, the analogous methodology was used, considering differences with respect to soft skills.

Advanced statistical methods require the use of adequate software. For the purpose of this article, the IBM SPSS program was used for non-parametric ANOVA and post hoc comparisons. Kernel estimation and calculations for relative distributions were carried out in $\mathrm{R}$ programme by functions available in reldist package (Handcock and Aldrich, 2002; Handcock, 2016). Versatile ggplot2 package (Wickham, 2016) was used for boxplots visualizations.

\section{Empirical results}

The distributions of earnings depending on the three levels of skills (low, medium, high) are illustrated by boxplots (Figure 1). Due to the occurrence of outliers and extreme values, the charts based on the linear scale would be hard to read. Hence, the logarithmic transformation of the coordinates was done, which takes place after the statistics are calculated and allows us to improve the possibilities of data visualization, namely in the case of highly skewed distributions. The first insight into data on earnings with respect to the skills level reveals some regularities. Firstly, people declaring higher skills earn on average more and this relationship is true for each of the competence under consideration. Secondly, the positive skewness of distribution occurs for all variables. Thirdly, a large number of outliers and high extreme values is present for every skill category. Fourthly, the largest variation coefficients occur in the group of people assessing their skills as low. 
Figure 1. Boxplots illustrating distributions of earnings depending on the level of skills
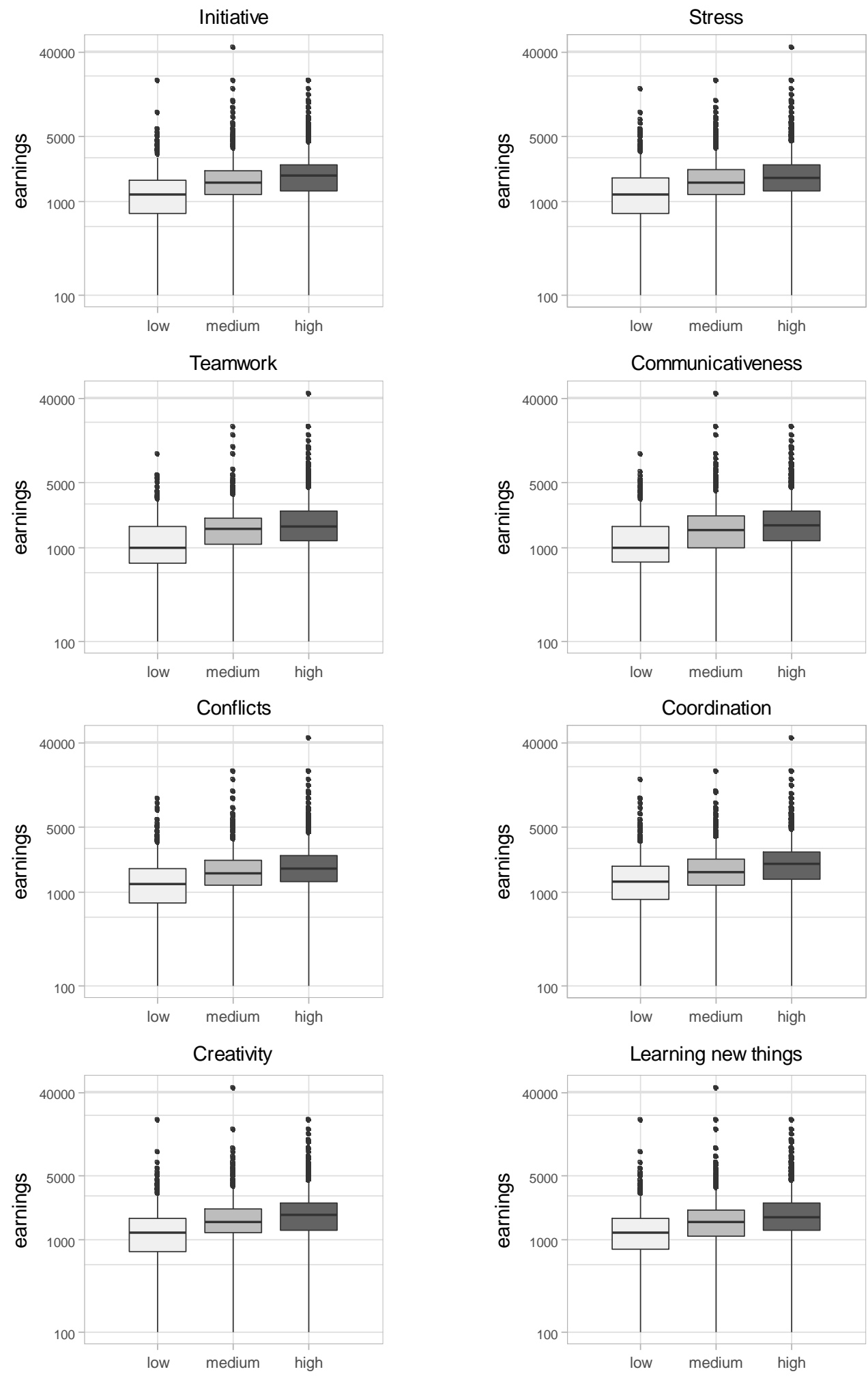

Source: own elaboration. 
Figure 2. Kernel estimation of distributions of logarithmic earnings depending on the level of skills
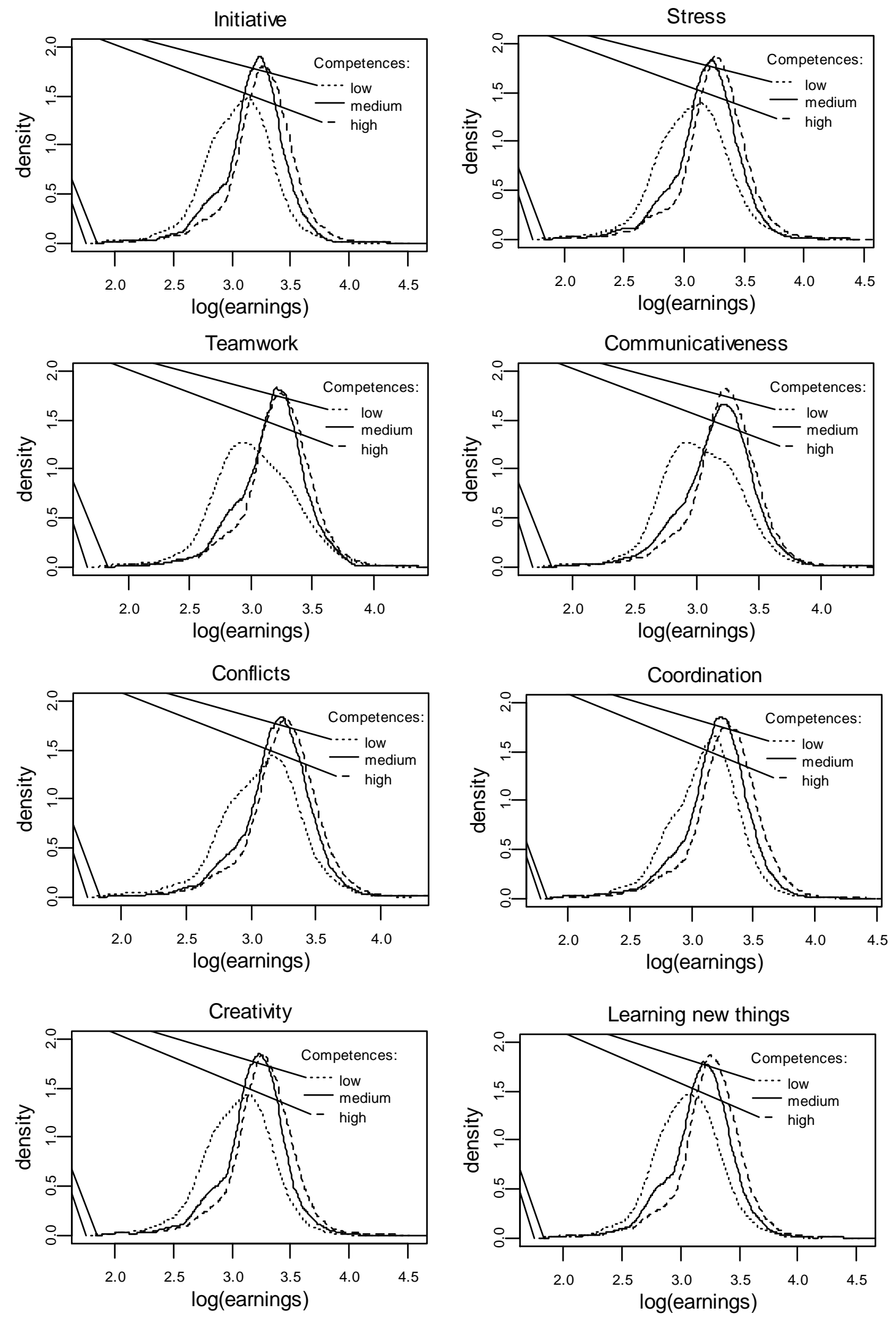

Source: own elaboration. 
Another and perhaps more accurate way of comparing earnings distributions is to estimate and plot their probability density functions. The presence of outliers and extreme values suggest that the logarithmic transformation of earnings should precede the procedure in order to make comparisons easier. The estimation was done by a kernel smoothing method, not demanding any assumptions about the distributions. The results of the estimation are shown in Figure 2.

The distributions corresponding to medium and high skills have similar shapes, while the distribution matching low skills differs significantly from the others both in the sense of the central tendency and the form. It is apparent that the low self-assessment of skills is associated with lower earnings. Moreover, the distributions corresponding to low skills are characterized by a higher dispersion. This is particularly evident for teamwork and communicativeness skills. Coordination skills seem to be the only exception for which the distributions are relatively similar. However, it should be kept in mind that the plots present probability density functions estimated on the base of the logarithmic values, in which large differences regarding the right tail of distributions are reduced.

This preliminary exploration of data leads to several conclusions and allows us to formulate some hypotheses to be verified in the further part of this study:

$\mathrm{H} 1$. There are significant differences in earnings related to the category of soft skills.

$\mathrm{H} 2$. Earnings of people declaring low soft skills differ substantially from earnings of others.

H3. Differences in earnings are not the same for all skills under consideration.

The first insight into data also suggests that earnings are not normally distributed. The assumption of normality must be verified before the choice of procedures for testing the presented hypotheses. Therefore, the normality was checked by the Shapiro-Wilk test. The Shapiro-Wilk test statistic $W$ equals from $W=0,49066$ to $W=0,82808$ with corresponding $p$ values less than 0,001 , what shows strong evidence of non-normality. It implies that the assumptions of commonly used parametric statistical tests are not met. In particular, the twosample t-test or the one-way analysis of variance are not appropriate for comparing group means. It would also be inadvisable to use the logarithmic values because the results of tests performed on such data are often "not relevant for the original, non-transformed data" (Changyong et al., 2014, p.105). Hence, the Kruskal-Wallis test by ranks, which is a nonparametric method, is proposed to evaluate the differences in earnings. If the null hypothesis that several independent samples have the same distributions is rejected post hoc pairwise comparisons are carried out to identify particular patterns. Table 1 provides the Kruskal-Wallis test statistics, and Table 2 presents the results of the pairwise comparisons.

Table 1. Evaluation of differences in distributions of earnings due to the level of skills - results of the Kruskal-Wallis test by ranks

\begin{tabular}{|c|c|}
\hline Skill & Test statistic \\
\hline Initiative & $569,994^{* * *}$ \\
\hline Stress & $455,456^{* * *}$ \\
\hline Teamwork & $248,334^{* * *}$ \\
\hline
\end{tabular}


Communicativeness

Conflicts

Coordination

Creativity

Learning new things
$284,813^{* * *}$

$375,727^{\star \star \star}$

$532,300^{* * *}$

$561,175^{\star * *}$

$477,634^{* * *}$

Source: own computations based on survey data. Note: ${ }^{* \star *} p<0,001$

Table 2. Pairwise tests of differences in earnings due to the level of skills - Dunn's procedure with Bonferroni corrections of $p$-values

\begin{tabular}{|c|c|c|}
\hline Skill & Compared levels & Test statistic \\
\hline & low - medium & $-978,446^{* * *}$ \\
\hline \multirow[t]{3}{*}{ Initiative } & low - high & $-1551,404^{\star \star *}$ \\
\hline & medium - high & $-572,958^{* * *}$ \\
\hline & low - medium & $-881,253^{* * *}$ \\
\hline \multirow[t]{3}{*}{ Stress } & low - high & $-1396,606^{\star * *}$ \\
\hline & medium - high & $-515,353^{* * *}$ \\
\hline & low - medium & $-967,525^{\star * *}$ \\
\hline \multirow[t]{3}{*}{ Teamwork } & low - high & $-1350,462^{* \star \star}$ \\
\hline & medium - high & $-383,209^{* * *}$ \\
\hline & low - medium & $-973,217^{\star \star *}$ \\
\hline \multirow[t]{3}{*}{ Communicativeness } & low - high & $-1375,832^{* * *}$ \\
\hline & medium - high & $-402,615^{\text {***}}$ \\
\hline & low - medium & $-857,796^{* * *}$ \\
\hline \multirow[t]{3}{*}{ Conflicts } & low - high & $-1251,091^{\text {***}}$ \\
\hline & medium - high & $-393,294^{* * *}$ \\
\hline & low - medium & $-752,976^{\star * *}$ \\
\hline \multirow[t]{3}{*}{ Coordination } & low - high & $-1349,761^{\text {***}}$ \\
\hline & medium - high & $-596,785^{\star * *}$ \\
\hline & low - medium & $-991,384^{* * *}$ \\
\hline \multirow[t]{3}{*}{ Creativity } & low - high & $-1530,138^{\star * *}$ \\
\hline & medium - high & $-538,754^{* * *}$ \\
\hline & low - medium & $-879,074^{\star * *}$ \\
\hline \multirow[t]{2}{*}{ Learning new things } & low - high & $-1479,828^{\star * *}$ \\
\hline & medium - high & $-600,754^{\star \star *}$ \\
\hline
\end{tabular}

Source: own computations based on survey data. Note: ${ }^{* \star \star} p<0,001$

The statistics of the Kruskal-Wallis test displayed in Table 1 clearly indicate that regardless of the skill considered, the null hypothesis should be rejected. Hence, earnings distributions 
corresponding to three categories (low, medium and high skills) are not the same. The highest test statistics are observed for entrepreneurship/showing initiative and creativity while the lowest for teamwork and communicativeness/clear expression of thoughts. The test proves that there are significant differences but does not provide the answer about their nature. More precise conclusions can be drawn from post hoc tests (Table 2). Pairwise comparisons show that significant differences in earnings are observed for each skill and each combination of levels. It is worth mentioning that the highest absolute values of the test statistic occur in low - high skills comparisons, and the smallest in the case of medium-high skills. The results vary across the skills under consideration. Thus, the one-way ANOVA on ranks confirms suppositions made in the preliminary phase of the analysis.

The results of the statistical tests show that the earnings distributions differ significantly, but the problem is that they do not give a detailed insight into the character and the magnitude of the discrepancies. The question that arises is how to describe differences in distributions more comprehensively. This goal can be achieved by using the relative distribution methods. This technique allows us to compare two distributions corresponding to the reference and the comparison group. In further considerations, these groups are formed of individuals declaring low and high skills, respectively. This choice results from the previous considerations, where it was shown that the group characterized by low skills significantly differs in terms of earnings from the others. Therefore it was chosen as the reference group.

The relative density functions with respect to particular skills are indicated by solid lines in Figure 3. A relative density shows how the individuals from the comparison group are arranged at particular quantiles of the distribution corresponding to the reference group. If distributions in the two groups were the same, the relative distribution would be uniform, and the relative probability density function would be a constant function equal to 1 . This is not obviously the case. The solid curves in Figure 3 confirm differences between the distributions. For upper deciles, the relative density function values are greater than 1, what demonstrates that the proportion of individuals from the comparison group (high skills) is considerably greater than that of the reference group (low skills). It is interesting to note that in each case (except for teamwork) the values of the functions grow rapidly in the 9th and 10th deciles reaching ca. 3, so high-skilled persons are about three times as likely as low-skilled respondents to appear at the upper end of the earnings scale. Thus, persons with higher skills are far more likely to have better earnings. On the contrary, very low values on the left side of the plots (bottom deciles) reveal that there are a lot fewer individuals who possess a high level of soft skills and report low earnings. This statement is true at least up to 6th-7th decile depending on the skill under consideration. The conclusion is straightforward: a strong shift towards higher earnings is observed in the comparison group.

The authors of the reldist $R$ package offer a supplementary visual tool to facilitate the interpretation of the differences in distributions, namely decile bar charts. They can be plotted as additional charts or superimposed on the relative density estimates as in Figure 3 . If distributions were the same in both groups, all bars would have the same height equal to 1. A bar lower than 1 means that in a given decile of the reference group there is less than $10 \%$ of individuals from the comparison group and vice versa - a bar higher than 1 indicates that in a given decile of the reference group there is more than $10 \%$ of individuals from the comparison group. 
Figure 3. Relative distributions of earnings in the low skills (reference) groups and high skill groups

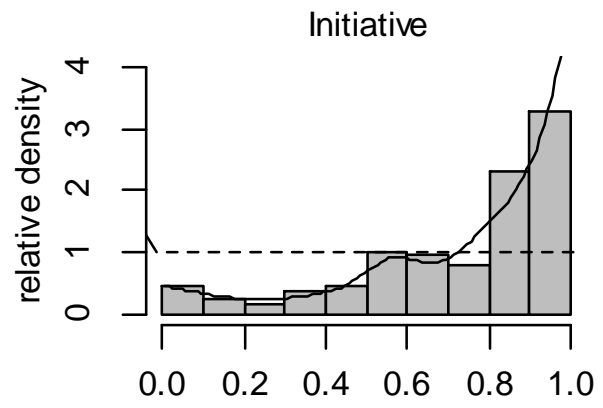

proportion of the reference group

Teamwork

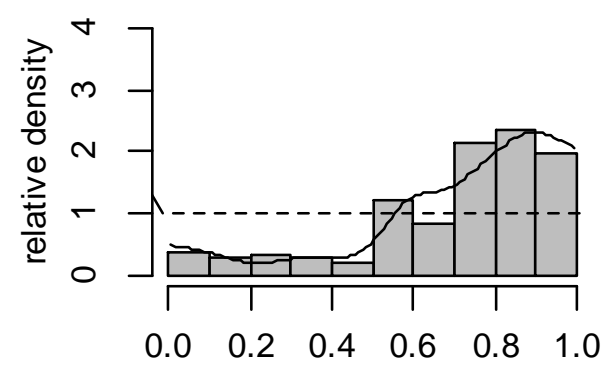

proportion of the reference group

Conflicts

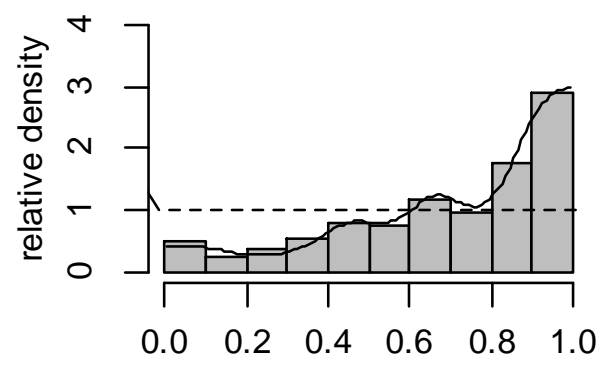

proportion of the reference group

Creativity

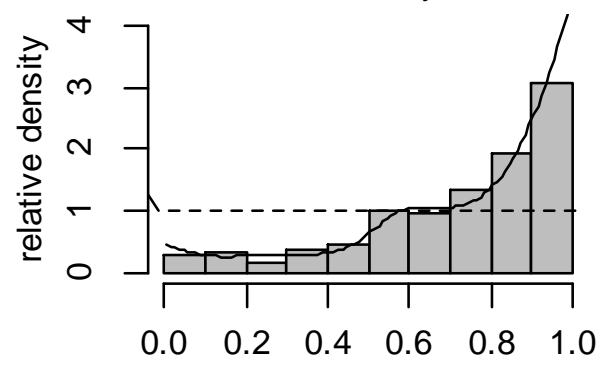

proportion of the reference group

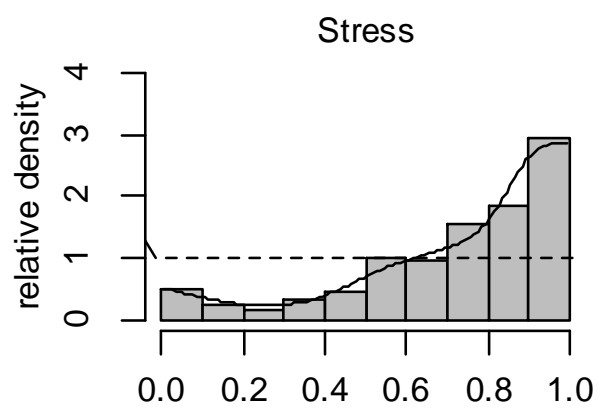

proportion of the reference group

Communicativeness

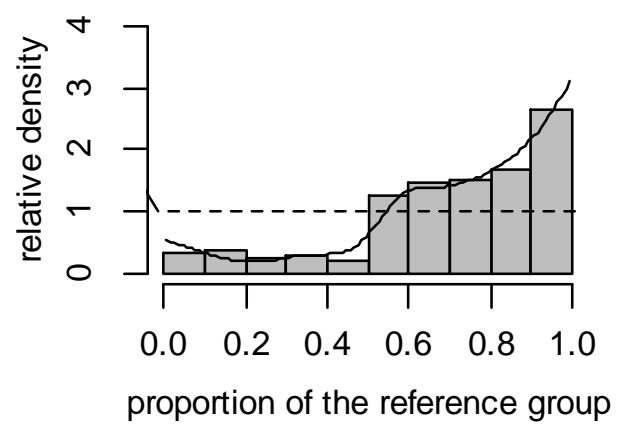

Coordination

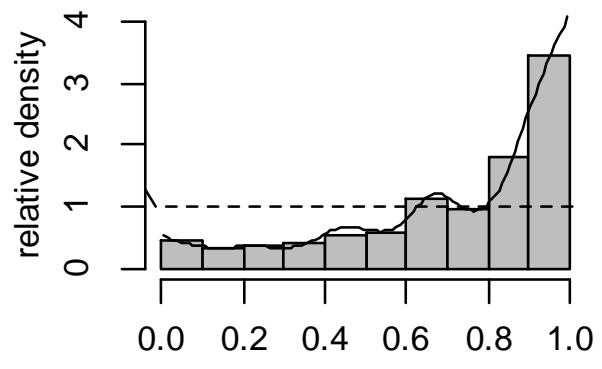

proportion of the reference group

Learning new things

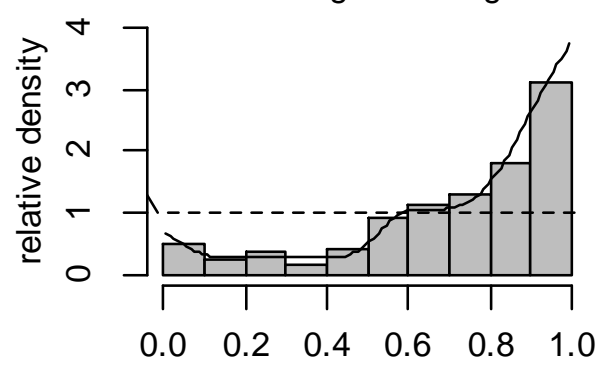

proportion of the reference group

Source: own elaboration. 
The bars in Figure 3 have a characteristic pattern in case of most considered skills as they are situated below 1 in the lower deciles while in the upper deciles exceed 1 considerably. The highest bars in 10th decile are observed for such skills as entrepreneurship/showing initiative and coordination of the work of other employees. It shows that these two skills influence the earnings the most noticeably. A specific pattern occurs in the case of the teamwork. Although the general rule of higher earnings accompanying higher skills is apparent, it is the only instance for which the maximum advantage was noted not in the 10th decile. It seems that the teamwork ability is not as strongly associated with earnings as other soft skills.

The representation by decile intervals presented in Figure 3 can be used to identify the shortages and surpluses in a numerical way providing information for precise comparisons. Table 3 shows the surpluses of individuals from the comparison group in the 9th and 10th decile of the reference group.

Table 3. Surplus of persons from the comparison group in the ninth and tenth deciles of the reference group

\begin{tabular}{lccc}
\hline \multicolumn{1}{c}{ Skill } & $\begin{array}{c}\text { Surplus in 9th decile } \\
\text { (percentage points) }\end{array}$ & $\begin{array}{c}\text { Surplus in 10th } \\
\text { decile } \\
\text { (percentage points) }\end{array}$ & $\begin{array}{c}\text { Surplus in 9th and } \\
\text { 10th deciles together } \\
\text { (percentage points) }\end{array}$ \\
\hline Initiative & 13,0 & 23,0 & 36,0 \\
Coordination & 8,0 & 24,3 & 32,3 \\
Creativity & 9,3 & 20,9 & 30,2 \\
Learning new things & 8,2 & 21,1 & 29,3 \\
Stress & 8,3 & 19,6 & 27,9 \\
Conflicts & 7,8 & 19,2 & 27,0 \\
Communicativeness & 7,0 & 16,4 & 23,4 \\
Teamwork & 13,5 & 9,7 & 23,2 \\
\hline
\end{tabular}

Source: own computations based on survey data.

The total surplus is a measure which allows us to set in order skills from those that give the most considerable financial advantage to those that give the smallest. Table 3 is presented according to the decreasing importance of skills. The biggest inequalities are observed for entrepreneurship/showing initiative, coordination of the work of other employees and creativity (the total surplus over 30 percentage points), while the lowest for communicativeness/clear expression of thoughts and teamwork. Nevertheless, for each skill, the total surplus exceeds 20 percentage points, which confirms once again the hypothesis about the association between the soft skills level and the amount of earnings. 


\section{Conclusions}

Although the role and the importance of skills and competencies in the knowledge-based economy are widely discussed in recent years in Poland, there are not many quantitative studies on associations between skills and labor market outcomes. This research tries to describe differences in earnings in relation to the declared level of soft skills categorized as low, medium and high. Various statistical methods are applied to examine the properties of earnings distributions with respect to skills level. The study is based on data from a nationwide survey on human capital comprising over six thousand responses.

The main results of the study show that there are statistically significant differences in earnings between groups characterized by different levels of skills. These findings are in line with the outcomes obtained by other researchers, although the analytical approaches differ. Numerous authors apply regression models to examine relations between skills level and wages. As data on cognitive skills are available from various surveys, the evaluation of their impact on labour market outcomes can be found in many studies. Positive relationships are proved among others in papers by Barone and Van de Werfhorst (2011), Burski et al. (2013), Castex and Kogan-Dechter (2014), Czarnik et al. (2011), Hanushek et al.(2015), Czarnik and Turek (2015), Hanushek et al. (2016). Another common approach is to estimate the skill premium by the original Mincerian model including years of schooling and potential work experience as regressors. The advantage is the accessibility of the data, but as years of schooling are far more general indicator than skills level, results derived from such analyses are not fully comparable with the outcomes from this study. It should be underlined that the measurement of soft skills encounters many problems and limitations. Balcar (2014), in his comprehensive overview on soft skills and their wage returns, claims that such competencies can be evaluated directly by questioning individuals or approximated indirectly by tasks. This study is based on data collected in a nationwide survey by using the first method. The overview of 11 papers by Bacar (2014) shows that regardless of the measurement approach, there are associations between soft skills and earnings. These findings are consistent with the results concerning the Polish labor market described in this paper. In the Polish literature, self-reported items representing non-cognitive skills to some extent close to soft skills were analyzed by Palczyńska (2018) who also found significant relationships between personal traits, cognitive skills and wages.

Additionally, the hypothesis that the discrepancies in earnings are not the same for all skills under consideration was confirmed in this research. Moreover, the relative distribution methods show that the shapes of earnings distributions differ substantially. The author also proposed how to compare the importance of particular skills using the surpluses in decile intervals. This leads to the conclusion that such skills as entrepreneurship/showing initiative, coordination of the work of other employees and creativity are most appreciated.

There are certain limitations associated with this research. First of all, an objection might be raised on the data which are subjective in nature. The information on skills used in this study comes from the self-assessment done by the respondents of the survey. Therefore, bias might be expected. The problem is that there is no precise, objective, nationwide data on the level of soft skills of individuals, and it is almost impossible that such information will be available in the future. Thus, soft skills are not easily measurable, and some approximation of their level must be made. Other studies mentioned in the literature review of this paper are also based on data from surveys 
or use an indirect way of measurement. The second limitation is that the list of soft skills which were assessed in the survey on human capital does not reflect all employers' expectations. The third problem is that respondents gave answers about their net monthly earnings. If the gross wages were analyzed, the outcomes could be different. It would be very interesting to evaluate the importance of skills with respect to the net and gross earnings, but there is no available data for such comparisons. Nevertheless, in the author's opinion, this research is based on the best and most comprehensive data possible at the moment and gives an insight into relations between soft skills and earnings. Eventually, it should also be underlined that the methods and the obtained results do not imply causal conclusions.

The subject discussed in this paper indicates ample opportunities for further research. Particularly, nonparametric methods as kernel estimation and relative distributions seem to be a very useful tool in evaluating the relationships of skills and earnings. This methodology does not require the normality assumption and gives a more accurate insight into the data, making it possible to compare the shapes of distributions and not only their characteristics. Additional covariates as gender, place of residence or age of workers may be included in analyses. Another possible approach is to seek for one composite indicator of soft skills and refer it to the level of earnings. Further studies can also be carried out in the direction of identification of changes over time as the survey on human capital provides comparable data from years previous to 2014 .

\section{References}

ALDERSON, A. S., BECKFIELD, J., NIELSEN, F. (2005). Exactly how has income inequality changed? Patterns of distributional change in core societies. International Journal of Comparative Sociology, 46(5-6), 405-423. https://doi.org/10.1177/0020715205059208

ALDERSON, A. S., DORAN, K. (2010). How has income inequality grown? The reshaping of the income distribution in LIS countries. Inequality and The Status of The Middle Class: Lessons from the Luxembourg Income Study, Luxembourg.

ANDREWS, J., HIGSON, H. (2008). Graduate employability, 'soft skills' versus 'hard' business knowledge: A European study. Higher education in Europe, 33(4), 411-422. https://doi.org/10.1080/03797720802522627

BALCAR, J. (2014). Soft skills and their wage returns: Overview of empirical literature. Review of Economic Perspectives, 14(1), 3-15. https://doi.org/10.2478/revecp-2014-0001

BARONE, C., VAN DE WERFHORST, H. G. (2011). Education, cognitive skills and earnings in comparative $\quad$ perspective. International Sociology, 26(4), 483-502. https://doi.org/10.1177/0268580910393045

BORGHANS, L., GREEN, F., MAYHEW, K. (2001). Skills measurement and economic analysis: an introduction. Oxford Economic Papers, 375-384. https://doi.org/10.1093/oep/53.3.375

BRUNELLO, G., SCHLOTTER, M. (2011). Non-cognitive skills and personality traits: Labour market relevance and their development in education \& training systems. IZA Discussion Paper No. 5743. 
BURSKI, J., CHŁOŃ-DOMIŃCZAK, A., PALCZYŃSKA, M., RYNKO, M., ŚPIEWANOWSKI, P. (2013), Umiejętności Polaków - wyniki Międzynarodowego Badania Kompetencji Osób Dorosłych (PIAAC), Instytut Badań Edukacyjnych, Warszawa.

CASTEX, G., KOGAN DECHTER, E. (2014). The changing roles of education and ability in wage determination. Journal of Labor Economics, 32(4), 685-710. https://doi.org/10.1086/676018

CHANGYONG, F. E. N. G., HONGYUE, W. A. N. G., NAIJI, L. U., TIAN, C. H. E. N., HUA, H. E., YING, L. U. (2014). Log-transformation and its implications for data analysis. Shanghai archives of psychiatry, 26(2), 105.

CIMATTI, B. (2016). Definition, development, assessment of soft skills and their role for the quality of organizations and enterprises. International Journal for Quality Research, 10(1), 97-130.

COBB-CLARK, D. A., TAN, M. (2011). Noncognitive skills, occupational attainment, and relative wages. Labour Economics, 18(1), 1-13. https://doi.org/10.1016/j.labeco.2010.07.003

CONTOYANNIS, P., WILDMAN, J. (2007). Using relative distributions to investigate the body mass index in England and Canada. Health economics, 16(9), 929-944. https://doi.org/10.1002/hec.1240

CZARNIK, SZ., STRZEBOŃSKA, A., SZKLARCZYK, D., KELER, K. (2011), Polki i Polacy na rynku pracy. Raport z badań ludności w wieku produkcyjnym realizowanych w 2010 r. w ramach projektu „Bilans Kapitału Ludzkiego”, Polska Agencja rozwoju Przedsiębiorczości, Warszawa.

CZARNIK, SZ., TUREK, K. (2015), Polski rynek pracy - aktywność zawodowa i struktura wykształcenia. Na podstawie badań ludności zrealizowanych w 2014 roku w ramach V edycji projektu Bilans Kapitału Ludzkiego, Polska Agencja Rozwoju Przedsiębiorczości, Warszawa.

DEMING, D. J. (2017). The growing importance of social skills in the labor market. The Quarterly Journal of Economics, 132(4), 1593-1640. https://doi.org/10.1093/qje/qjx022

DUNN, O. J. (1964). Multiple Comparisons Using Rank Sums. Technometrics, 6, 241-241. https://doi.org/10.1080/00401706.1964.10490181

EDIN, P. A., FREDRIKSSON, P., NYBOM, M., OCKERT, B. (2018). The rising return to noncognitive skill, IZA Institute of Labor Economics Discussion Paper Series No. 10914

GRZEŚKOWIAK, A. (2018). Poziom kompetencji twardych a wysokość zarobków-ocena za pomocą wybranych metod nieparametrycznych. Acta Universitatis Lodziensis. Folia Oeconomica, 5(338), 143-156. https://doi.org/10.18778/0208-6018.338.09

GRZEŚKOWIAK, A. (2017). Relacje pomiędzy poziomem kompetencji twardych a wysokością zarobków w świetle badań dotyczących kapitału ludzkiego w Polsce. Zeszyty Naukowe Wyższej Szkoły Ekonomiczno-Społecznej w Ostrołęce, (26), 64-73. 
HANDCOCK, M. S., MORRIS, M. (1998). Relative distribution methods. Sociological Methodology, 28(1), 53-97. https://doi.org/10.1111/0081-1750.00042

HANDCOCK, M. S., MORRIS, M. (1999). Relative distribution methods in the social sciences. Springer-Verlag, New York.

HANDCOCK, M. S., ALDRICH, E. M. (2002). Applying relative distribution methods in R. Working Paper no. 27, Center for Statistics and the Social Sciences University of Washington, Seattle. https://doi.org/10.2139/ssrn.1515775

HANDCOCK, M. S. (2016). Relative Distribution Methods. Version 1.6-6. Project home page at http://www.stat.ucla.edu/ handcock/RelDist.

HANUSHEK, E. A., WOESSMANN, L. (2008). The role of cognitive skills in economic development. Journal of economic literature, 46(3), 607-68. https://doi.org/10.1257/jel.46.3.607

HANUSHEK, E. A., SCHWERDT, G., WIEDERHOLD, S., WOESSMANN, L. (2015). Returns to skills around the world: Evidence from PIAAC. European Economic Review, 73, 103-130. https://doi.org/10.1016/j.euroecorev.2014.10.006

HANUSHEK, E. A., SCHWERDT, G., WIEDERHOLD, S., WOESSMANN, L. (2016).Coping with Change: International Differences in the Returns to Skills, IZA Discussion Papers No. 10249. https://doi.org/10.3386/w22657

HEALY, T., CÔTÉ, S. (2001). The Well-Being of Nations: The Role of Human and Social Capital. Education and Skills. Organisation for Economic Cooperation and Development, Paris, France.

HECKMAN, J. J., STIXRUD, J., URZUA, S. (2006). The effects of cognitive and noncognitive abilities on labor market outcomes and social behavior. Journal of Labor economics, 24(3), 411-482. https://doi.org/10.1086/504455

KABUDULA, C. W., HOULE, B., COLLINSON, M. A., KAHN, K., TOLLMAN, S., CLARK, S. (2017). Assessing changes in household socioeconomic status in rural South Africa, 20012013: a distributional analysis using household asset indicators. Social indicators research, 133(3), 1047-1073. https://doi.org/10.1007/s11205-016-1397-z

KRUSKAL, W. H, WALLIS, W. A (1952). Use of ranks in one-criterion variance analysis. Journal of the American Statistical Association, 47 (260), 583-621. https://doi.org/10.1080/01621459.1952.10483441

KYLLONEN, P. C. (2013). Soft skills for the workplace. Change: The Magazine of Higher Learning, 45(6), 16-23. https://doi.org/10.1080/00091383.2013.841516

LINDQVIST, E., VESTMAN, R. (2011). The labor market returns to cognitive and noncognitive ability: Evidence from the Swedish enlistment. American Economic Journal: Applied Economics, 3(1), 101-28. https://doi.org/10.1257/app.3.1.101 
MATTESON, M. L., ANDERSON, L., BOYDEN, C. (2016). "Soft Skills": A Phrase in Search of Meaning. portal: Libraries and the Academy, 16(1), 71-88. https://doi.org/10.1353/pla.2016.0009

MOESLUND, T. B., HILTON, A., KRÜGER, V., SIGAL, L. (2011). Visual analysis of humans. Springer London. https://doi.org/10.1007/978-0-85729-997-0

MORRIS, M., BERNHARDT, A. D., HANDCOCK, M. S. (1994). Economic inequality: New methods for new trends. American Sociological Review, 59(2), 205-219. https://doi.org/10.2307/2096227

MYSÍKOVÁ, M. (2011). Personal earnings inequality in the Czech Republic. IES Working Paper, $11 / 2011$

PALCZYŃSKA, M. (2018). Wage premia for skills: the complementarity of cognitive and noncognitive skills. IBS Working Paper 09/2018.

PARZEN, E. (1962). On Estimation of a Probability Density Function and Mode. The Annals of Mathematical Statistics, 33(3), 1065-1076. https://doi.org/10.1214/aoms/1177704472

RAINSBURY, E., HODGES, D., BURCHELL, N. LAY, M. C. (2002). Ranking workplace competencies: Student and graduate perceptions. Asia-Pacific Journal of Cooperative Education, 3(2), 8-18.

RAZALI, N. M., WAH, Y. B. (2011). Power comparisons of Shapiro-Wilk, Kolmogorov-Smirnov, Lilliefors and Anderson-Darling tests. Journal of statistical modeling and analytics, 2(1), 21 33.

RIZZO, M. L. (2019). Statistical computing with R. Chapman and Hall/CRC, Boca Raton. https://doi.org/10.1201/9780429192760

ROBLES, M. M. (2012). Executive perceptions of the top 10 soft skills needed in today's workplace. Business Communication $\quad$ Quarterly, 75(4), 453-465. https://doi.org/10.1177/1080569912460400

ROSENBLATT, M. (1956). Remarks on some nonparametric estimates of a density function. The $\begin{array}{llll}\text { Annals of } \quad \text { Mathematical } & \text { Statistics, }\end{array}$ https://doi.org/10.1214/aoms/1177728190

SARKAR, D. (2008). Lattice: multivariate data visualization with R. Springer Science \& Business Media. https://doi.org/10.1007/978-0-387-75969-2

SCHULZ, B. (2008). The importance of soft skills: Education beyond academic knowledge, Journal of Language and Communication, (June), 146-154.

SHAPIRO, S. S., WILK, M. B. (1965). An analysis of variance test for normality (complete samples). Biometrika, 52(3/4), 591-611. https://doi.org/10.1093/biomet/52.3-4.591 
SILVERMAN, B.W. (1986). Density estimation for statistics and data analysis, Chapman and Hall, London. https://doi.org/10.1007/978-1-4899-3324-9

WEINBERGER, C. J. (2014). The increasing complementarity between cognitive and social skills. Review of Economics and Statistics, 96(4), 849-861. https://doi.org/10.1162/REST_a_00449

WICKHAM, H. (2016). ggplot2: Elegant Graphics for Data Analysis. Springer-Verlag New York, 2016. https://doi.org/10.1007/978-3-319-24277-4 